\title{
Operation Results of a Photovoltaic System Interconnected to the Low Voltage Grid in Bogotá, Colombia
}

\author{
J. Aristizábal, J. Camacho, A. Pérez, C. Páez, and I. Dyner
}

\begin{abstract}
In this work we present the results of monitoring a building integrated photovoltaic (BIPV) system which was installed in Bogota, Colombia. The system is functioning in the building of the Economics Department at the Central University and it is composed of a $900 \mathrm{~W}$ photovoltaic generator connected to the electrical grid through a $700 \mathrm{~W}$ inverter. A two-year monitoring process of the system and the meteorological variables allowed us to assess the energy performance, and correlate power production with solar radiation.
\end{abstract}

Index Terms-Irradiance, photovoltaic, solar energy, performance.

\section{INTRODUCTION}

A grid connected system is connected to a large independent grid which in most cases is the public electricity grid and feeds power into the grid. They vary in size from a few $\mathrm{kWp}$ for residential purposes to solar power stations up to tens of GWp. This is a form of decentralized electricity generation [1].

Growing of PV for electricity generation is one of the highest in the field of the renewable energies and this tendency is expected to continue in the next years [2].

Grid connection and extension costs are significant factors for integrating renewable energy sources-electricity (RES-E) generation technologies into an existing electricity network. Prices of both PV and balance of system components are decreasing following a trend of increased production and improved technology. This explains the high amount of subsidies for R\&D and application of PVs in industrialized countries [3].

In a photovoltaic system interconnected to the electrical grid, a part or all of the electrical power generated is delivered to the electricity distribution grid. A BIPV system has fewer components than an autonomous installation mainly due to the fact that it does not require an energy storage system (batteries) nor a regulator as a result. In these facilities, the electrical powers generated by the photovoltaic modules go to the inverter directly, which transforms and delivers it to the grid after having passed through the corresponding measurement and protection elements. Therefore, the power that a BIPV system delivers to the grid is that produced by its generator minus the energy lost by its inverter.

Manuscript received January 2, 2015; revised April 12, 2015. This work was supported by the Engineering Faculty of Central University, Colombia.

A. J. Aristizábal, C. Páez, and I. Dyner are with Jorge Tadeo Lozano University, Colombia (e-mail: andresj.aristizabalc@utadeo.edu.co, carlosa.paezch@utadeo.edu.co, isaac.dynerr@utadeo.edu.co).

J. Camacho and A. Pérez are with Central University, Colombia (e-mail: jcamachoc1@ucentral.edu.co, aperez@ucentral.edu.co).
It is expected that the systems connected to the grid produce a good development level so that their costs get reduced, and their implementation be encouraged publicly given the environmental and sociopolitical benefits they can yield.

In Colombia, in 2001, the Law 697 was decreed through which rational and efficient use of energy (RUE) is declared with the aim of promoting the use of renewable energy as a matter of national interest and commitment to the environment. Subsequently, in May of 2014, the Law 1715 is decreed with the purpose of regulating the integration of non-conventional renewable energies to the national energy system. These government actions created new energy scenarios in matters of regulation, markets, economics, installation and technology in energy that pose a new challenge for the country [4].

In this work we present the results of monitoring a $900 \mathrm{~W}$ BIPV system carried out during the first two years of operation, using the same measurement system implemented by Aristizábal et al. $(2008,2011)$ and extensively described in other articles [5], [6]. The results indicate that the BIPV system generated $1525 \mathrm{kWh} /$ year in 2011 and $1551 \mathrm{kWh} /$ year in 2012 of AC power, while the efficiency of the photovoltaic generator was $13.67 \%$ in 2011 and $14.15 \%$ in 2012 on average.

\section{SYSTEM DESCRIPTION}

The BIPV system is composed of 5 polycrystalline silicon modules (Stream IS180M24/F), $180 \mathrm{~W}$ each, and a 700W SMA Sunny Boy 700US inverter. Due to the fact that the voltage required by the inverter to activate its maximum power follower circuit $\left(\mathrm{V}_{\mathrm{MPP}}\right)$ is in the range $125-200 \mathrm{~V}$, the 5 modules were connected in series. In this way, the total photovoltaic array power is $900 \mathrm{~W}$.

Fig. 1 shows the wiring circuit of the complete system composed of three main parts:

- The BIPV system composed of the PV array, the inverter and the protection elements.

- The monitoring system composed of solar radiation sensors, environmental temperature and electrical variables sensors, and the data acquisition system.

- The monitoring software implemented by using LabVIEW 2009.

The Sunny Boy 700US inverter complies with the requirements of the IEEE 929-2000 [7] standard in terms of electrical power quality: voltage harmonic distortion, harmonic components, variations in voltage and frequency, and flicker and power factor presence. The system was monitored to analyze the energy performance and the power 
quality generated during the years 2011 and 2012 .

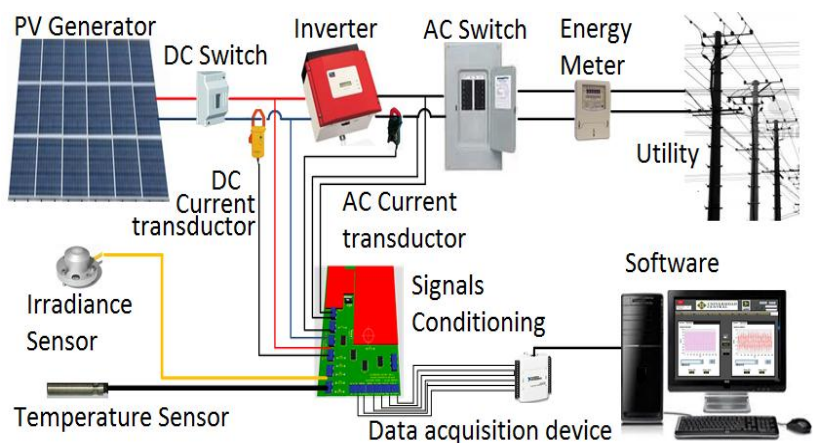

Fig. 1. Block diagram of the grid-connected system, including the devices constituting the monitoring system.

\section{MONITORING SYSTEM}

Using the monitoring system developed by Aristizábal et al. [5] and presented in Fig. 2, the signals described above were acquired and stored in the PC memory for further analysis.

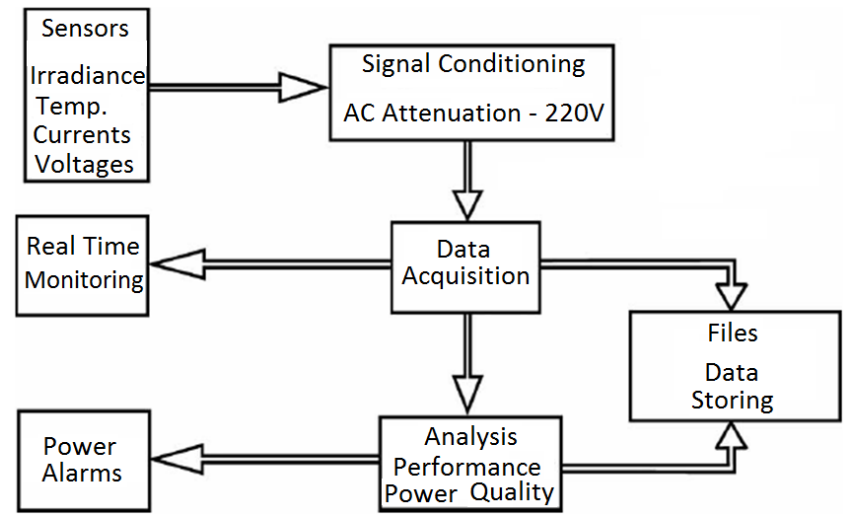

Fig. 2. Block diagram of the monitoring system.

The sensors' technical specifications are the following:

1) D.C. Voltage: An electronic attenuator circuit with a 0 $-10 \mathrm{~V}$ output was used.

2) D.C. Current: We used a clamp-on ammeter, reference Fluke i410 with a measuring range of $1-400 \mathrm{~A}$, and a 1 $\mathrm{mV} / \mathrm{A}$ output.

3) A.C. Voltage: We used a biphasic transformer with a $0-$ $6 \mathrm{~V}$ output.

4) A.C. Current: We used a clamp-on ammeter; reference Fluke i200 s with a measuring range of $0.1-24 \mathrm{~A}$, and a $100 \mathrm{mV} / \mathrm{A}$ output.

5) Solar Radiation: An SP Lite 2 silicon pyranometer model with a measurement range of $400-1100 \mathrm{~nm}$ and a sensitivity of 60 to $100 \mu \mathrm{V} / \mathrm{W} / \mathrm{m}^{2}$.

6) Environment temperature: We used a $10 \mathrm{k} \Omega$ NTC thermistor at the standard temperature of $25^{\circ} \mathrm{C}$. The electrical resistor variation of this device in function of temperature was the characteristic used to determine real temperature.

Each sensor was fitted out electronically prior to connecting the signals to the data acquisition system, composed of a USB DAQ 6008 reference card that has 8 measurement channels, a 12-bit resolution and a sampling rate of $10 \mathrm{kS} / \mathrm{s}$.

By means of the LabVIEW software, the following analysis units were developed: signals configuration and acquisition, power quality, phase analysis and performance analysis.

Fig. 3 shows the front panel used to carry out the BIPV system's performance analysis.

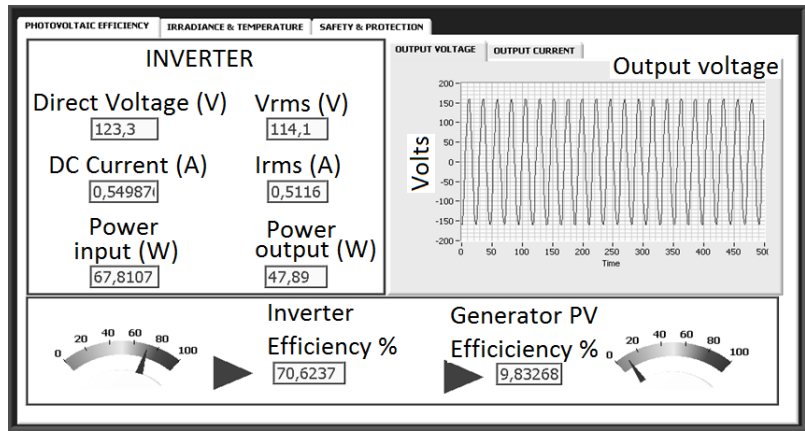

Fig. 3. Front panel used to analyze the BIPV system performance.

\section{PV SYSTEM PERFORMANCE RESULTS}

\section{A. PV Array Performance}

The PV generator performance is affected by the temperature and irradiance affecting solar cells.

Fig. 4 and Fig. 5 show the main results of the PV generator performance for 2011 and 2012.

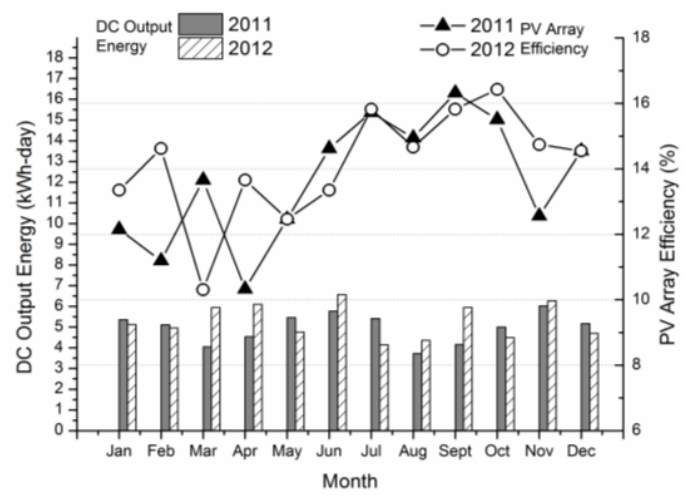

Fig. 4. Annual profile of the average daily DC energy and the PV array efficiency for 2011 and 2012.

The PV array efficiency recorded an average of $13.67 \%$ for the year 2011 and $14.15 \%$ for 2012; with a minimum of $10.30 \%$ in the month of April, 2012; and a maximum of $16.43 \%$ for the month of October in the same year. These results are due to the influence of temperature on the solar modules and changing conditions of cloudiness of the city of Bogotá [5] as shown in Fig. 5.

The DC energy production of the PV array was 1638 $\mathrm{kWh} /$ year in 2011, and $1711 \mathrm{kWh} /$ year in 2012. These results coincide with a higher solar radiation recorded in 2012 on the solar modules as shown in Fig. 5. The average DC power for the two monitoring years was $5.13 \mathrm{kWh} /$ day.

The year 2011 recorded the lowest solar radiation with a monthly average of $3.69 \mathrm{kWh} / \mathrm{m}^{2}$-day; being the months of March, May and August, the lowest with up to 2.21 $\mathrm{kWh} / \mathrm{m}^{2}$-day. April and November recorded the highest radiation with $4.59 \mathrm{kWh} / \mathrm{m}^{2}$-day. As to 2012 , the highest radiation was recorded in the month of May with 4.92 $\mathrm{kWh} / \mathrm{m}^{2}$-day, while the total annual average was 4.14 $\mathrm{kWh} / \mathrm{m}^{2}$-day. 


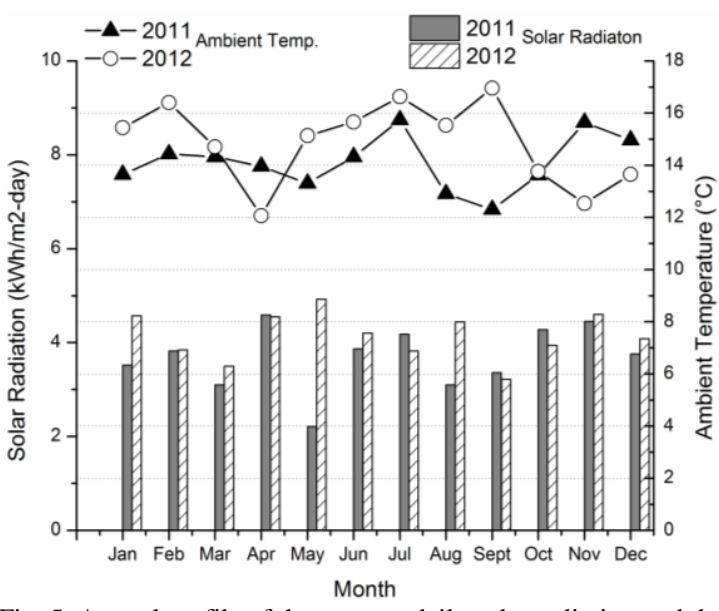

Fig. 5. Annual profile of the average daily solar radiation and the environment temperature on the PV array for 2011 and 2012.

The temperature variation for the two analysis years was between $12.06{ }^{\circ} \mathrm{C}$ to $15.74{ }^{\circ} \mathrm{C}$.

\section{B. Inverter Performance}

The power production generated by the inverter is shown in Fig. 6 along with the solar radiation profile for a sunny day between 6:00 am and 6:00 pm.

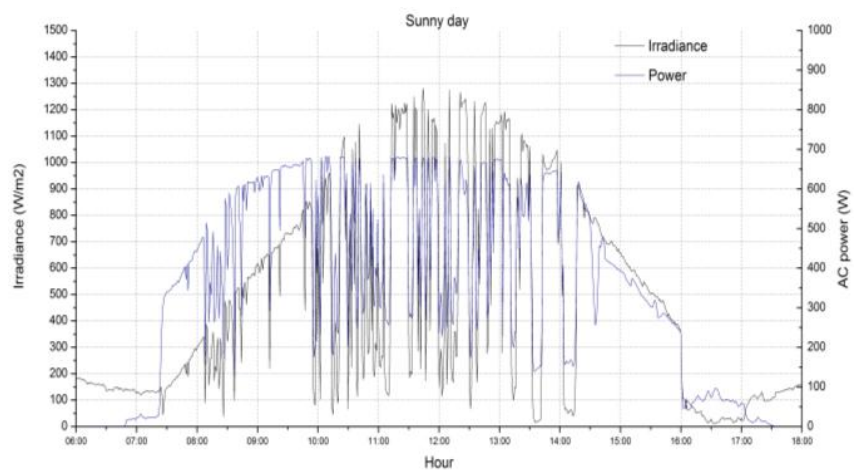

Fig. 6. System's irradiance and AC power variation for a sunny day.

You can observe a high radiation $\left(1280 \mathrm{~W} / \mathrm{m}^{2}\right)$ with changes that could be construed as the emergence of small clouds during short periods of time due to the climate behavior in Bogotá city.

This clearly shows a similar pattern between the AC power generated by the inverter and solar radiation; obviously due to the PV generator's photocurrent dependence on the incident photons energy. This bell-shaped behavior indicates a radiation increase between 11:00 am and 2:00 pm, and then it begins to fall to zero at the 5:30 pm approximately.

It is also clear that power is not generated in the early morning hours due to the fact that solar panels produce a voltage lower than $75 \mathrm{~V}$ which is not enough for the inverter to turn on and start the power delivery. Around 7:30 am, the inverter starts its operation, delivering power close to $350 \mathrm{~W}$.

Fig. 7 shows the inverter's efficiency variation as a function of the power level in a range varying between $20 \mathrm{~W}$ and $800 \mathrm{~W}$.

The results indicate that the inverter displays an efficiency above $80 \%$ when it reaches $200 \mathrm{~W}$; however, the efficiency decreases significantly when the power level decreases too, which indicates that the inverter's maximum efficiency can be achieved when the photovoltaic modules are in their maximum power point.

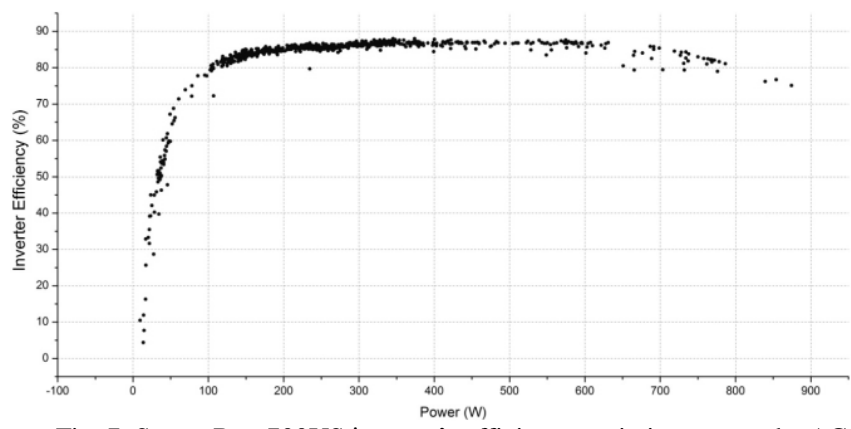

Fig. 7. Sunny Boy 700US inverter's efficiency variation versus the AC power generated.

On the other hand, the curve Fig. 7 is similar to that reported by the manufacturer, indicating that the inverter reaches efficiency close to $93 \%$ when the power is greater than 200W, which also indicates a photovoltaic system's correct operation achieving the maximum possible performance.

Fig. 8 compares the monthly inverter's efficiency average values, calculated from the data obtained for the years 2011 and 2012 .

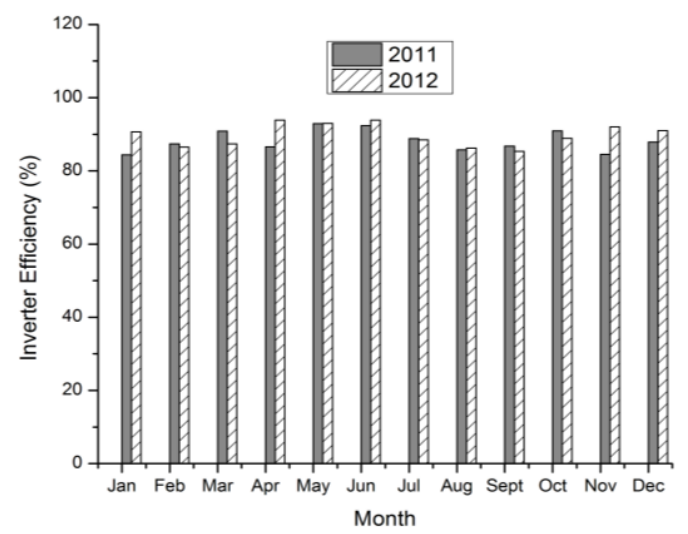

Fig. 8. Sunny Boy 700US inverter efficiency for 2011-2012.

The results reveal a monthly average efficiency of $89.8 \%$ for the two monitoring years varying between $84.4 \%$ and $93.8 \%$.

\section{PV System Performance}

Fig. 9 shows the whole PV system efficiency variation versus the $\mathrm{AC}$ power production generated by the inverter.

As it might be expected, the whole system efficiency is less than the PV array efficiency due to losses associated with the transformation of DC into AC power by the inverter. The most representative months of both years were July, September and October with values above $12 \%$, while the lowest months were March, April and May with values that ranged between $9 \%$ and $11 \%$. The whole system average efficiency for both years was $11.83 \%$.

On the other hand, the generation of AC energy was 3076 $\mathrm{kWh} /$ year for the full two years. The average AC energy for 2011 was $4.40 \mathrm{kWh} /$ day, and $4.52 \mathrm{kWh} /$ day for 2012 . The low levels of AC energy in Fig. 9 are caused by losses in transportation between the array and the PV inverter, and by low solar radiation days as well due to periods of rain in the country. 


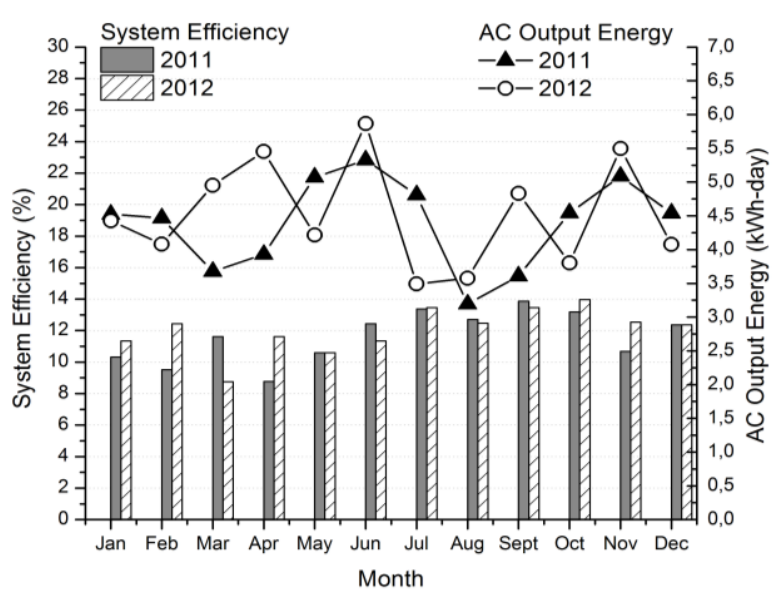

Fig. 9. PV system efficiency versus AC energy for 2011-2012.

Fig. 10 shows the flicker variation versus the power factor of the AC signal in the inverter's output.

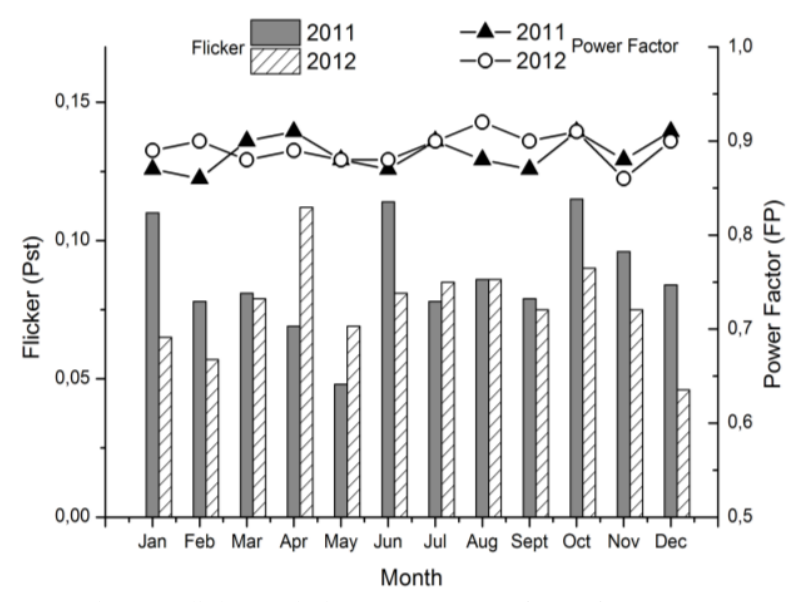

Fig. 10. Flicker variation versus power factor for 2011-2012.

The BIPV system's power quality was assessed taking into account the recommendations of the standard IEEE 929-2000 [7]. The quality of electrical power is related to the events or endeavors affecting the load due to potential problems in the supply of electric power.

The Flicker is defined as a disturbance visible to the human eye with a frequency between $15 \mathrm{~Hz}$ and $30 \mathrm{~Hz}$ that must not be present in interconnected systems. The monitoring system was developed taking into account the standard IEC 610004-15 [8] to analyze the flicker presence. The results showed that the flicker was always in values lower than 0.12 Pst (short time), indicating that it does not represent a danger to the human eye since they did not reach the allowable limit of 1 Pst.

The power factor analyzed as the relationship between the active power and the apparent power to the inverter outlet always registers values higher than 0.85 as required under the standard IEEE 929-2000.

Fig. 11 presents the system's frequency variation versus the AC voltage.

The results showed that the system frequency was never less than $59.95 \mathrm{~Hz}$ nor exceeded $60.05 \mathrm{~Hz}$, demonstrating the correct inverter operation, while the voltage was always maintained in $10 \%$ of the nominal voltage of the electrical grid. Finally, the THDv \% voltage harmonic distortion never exceeded $5 \%$ as required under the regulations.

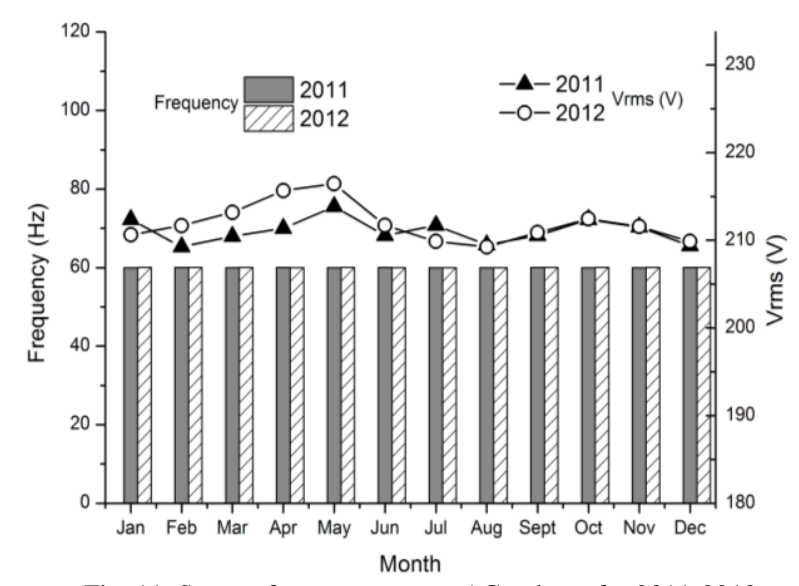

Fig. 11. System frequency versus AC voltage for 2011-2012.

\section{CONCLUSIONS}

From the research, we conclude the following:

1) The initial design of the photovoltaic system was meant to produce $1500 \mathrm{kWh} /$ year of AC power. This value was exceeded by $25 \mathrm{kWh} /$ year in 2011 and $51 \mathrm{kWh} /$ year more in 2012.

2) Solar radiation in Bogotá between 2011 and 2012 averaged $4.14 \mathrm{kWh} / \mathrm{m}^{2}$-day, allowing an increase in the $\mathrm{AC}$ power generation of the system with regard to what was originally calculated.

3) The energy quality parameters: voltage, frequency, power factor, flicker and \% THDv were all within the limits recommended by IEEE-929-2000.

4) Changes in the national energy regulations as well as support for funding power renewable generation systems could be incentives for people to install residential photovoltaic systems massively in Colombia.

\section{ACKNOWLEDGMENT}

The authors thank the Central University in Bogotá, Colombia, for the financial support received and the facilities offered.

\section{REFERENCES}

[1] B. Parida, S. Iniyan, and R. Goic, "A review of solar photovoltaic technologies," Renewable and Sustainable Energy Reviews, vol. 15, pp. 1625-1636, January 2011.

[2] IEA Photovoltaic Power Systems Program, "Trends in photovoltaic applications, survey report of selected IEA countries between 1992 and 2003," Report IEAPVPS T1-13, 2004.

[3] M. A. Eltawil and Z. Zhao, "Grid-connected photovoltaic power systems: Technical and potential problems - a review," Renewable and Sustainable Energy Reviews, vol. 14, pp. 112-129, July 2009.

[4] A. J. Aristizábal, I. Dyner, and C. Páez, “Generación distribuida de energía Eléctrica mediante energía solar fotovoltaica en la red de baja tensión de la universidad de Bogotá Jorge Tadeo Lozano," presented at the $2^{\text {nd }}$ International Congress of Sustainable Energy, Bogotá, 2014.

[5] A. J. Aristizábal and G. Gordillo. (2011). Performance and economic evaluation of the first grid - connected installation in Colombia, over 4 years of continuous operation. International Journal of Sustainable Energy. [Online]. 30(2). pp. 1-13. Available: http://dx.doi.org/10.1080/1478646X.2010.489948

[6] A. J. Aristizábal and G. Gordillo, "Performance monitoring results of the first grid-connected BIPV installation in Colombia," Renewable Energy, vol. 33, pp. 2475-2484, November 2008.

[7] Recommended Practice for Utility Interface of Photovoltaic (PV) Systems, IEEE Standard 6857901.

[8] Testing and Measurement Techniques - Flickermeter - Functional and Design Specifications, IEC Standard 2.0 B: 2010. 


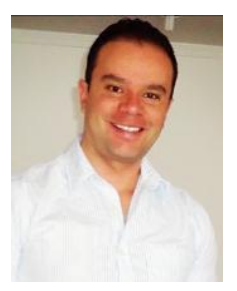

A. J. Aristizábal is the director of the master's degree of engineering in sustainable management of energy, in Jorge Tadeo Lozano University, Bogotá, Colombia. $\mathrm{He}$ has a Ph.D. degree of science in physics from National University of Colombia. His areas of interest are photovoltaic solar energy, virtual instrumentation, power quality, and energy sustainability.

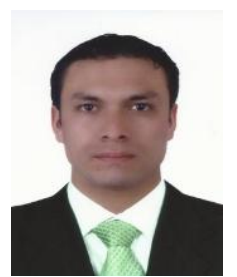

J. Camacho is an electronics engineer from the Central University, Bogota, Colombia. $\mathrm{He}$ has participated in research projects about artificial intelligence. His areas of interest are electronic instrumentation, renewable energy systems, control and robotics.

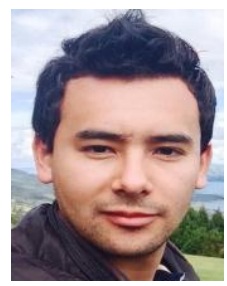

A. Pérez is an electronics engineer from the Central University, Bogota Colombia. His areas of interest are renewable energy systems, control and robotics.

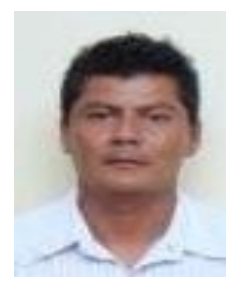

C. Páez is an electrical engineer from National University of Colombia, and he is a candidate for the master's degree of engineering in sustainable management of energy, from the Jorge Tadeo Lozano University, Bogotá, Colombia. He has extensive experience in the executive administration and management of energy projects. His areas of interest are renewable energy sources, optimization methods and models and energy markets.

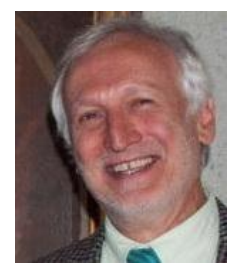

I. Dyner is the dean of the School of Natural Sciences and Engineering in the Jorge Tadeo Lozano University, Bogotá, Colombia. He has a Ph.D. degree in decision sciences from London University and a master's degree in statistics and operational research. His areas of interest are operational research, systems dynamics, strategy, regulation and energy. 


\section{Electrical Energy}


